\title{
Pre- and Postnatal Analysis of Chromosome 15q26.1 and 8p23.1 Deletions in Congenital Diaphragmatic Hernia
}

\author{
Mitesh Shetty $^{a}$ Jayarama Kadandale ${ }^{b}$ Sridevi Hegde ${ }^{a}$ \\ ${ }^{a}$ Department of Medical Genetics, Manipal Hospital, and ${ }^{b}$ Center for Human Genetics, Biotech Park, Bangalore, India
}

\author{
Key Words \\ Congenital diaphragmatic hernia · Deletion 8p23.1 . \\ Deletion 15q26.1 · FISH
}

\begin{abstract}
Congenital diaphragmatic hernia $(\mathrm{CDH})$ is defined as a protrusion of abdominal content into the thoracic cavity through an abnormal opening in the diaphragm present at birth. It is a common birth defect with high mortality and morbidity. Submicroscopic deletions of $15 q 26.1$ and 8 p23.1 have been reported in several cases of $\mathrm{CDH}$. We studied a total of 17 cases with CDH in pre- and postnatal samples using FISH probes. Deletion $15 q 26.1$ was seen in $1 / 17$ prenatal samples. There was no deletion for $8 p 23.1$ in all the samples analyzed. CDH has a genetic etiology, and deletion $15 q 26.1$ increases the risk of $\mathrm{CDH}$. Deletion $15 \mathrm{q} 26.1$ in a fetus with $\mathrm{CDH}$ is a predictor of poor prognosis. This deletion is also seen in a phenotype similar to Fryns syndrome. CDH identified pre- or postnatally should be investigated further to exclude a 15q26.1 deletion and enable appropriate parental counseling.
\end{abstract}

(c) 2015 S. Karger AG, Basel

Congenital diaphragmatic hernia $(\mathrm{CDH})$ is a malformation of the developing diaphragm in which the abdominal organs are pushed into the thorax. $\mathrm{CDH}$ is characterized by a variable defect in the diaphragm, pulmo- nary hypoplasia, and postnatal pulmonary hypertension. A diaphragmatic hernia is an emergency that requires surgery. Prevalence of $\mathrm{CDH}$ in newborns is $\sim 1$ in 3,000 [Holder et al., 2007]. The overall mortality rate for $\mathrm{CDH}$ remains high, despite advances in neonatal care. The development of the human diaphragm occurs between the 4 th and 12th week of gestation. CDH can be detected prenatally by an ultrasound examination performed during the second trimester in most affected infants. $\mathrm{CDH}$ can occur as an isolated defect, in combination with multiple congenital anomalies or as a part of a defined syndrome. Isolated $\mathrm{CDH}$ or nonsyndromic $\mathrm{CDH}$ is the only birth defect in $60 \%$ of the cases. The additional features such as pulmonary hypoplasia, cardiac dextroposition and left heart hypoplasia are usually considered as a part of $\mathrm{CDH}$. The mortality rate of isolated $\mathrm{CDH}$ is $10-20 \%$ lower than that of syndromic CDH [Pober, 2008]. Nonisolated or syndromic $\mathrm{CDH}$ accounts for $40 \%$ of $\mathrm{CDH}$. The single gene disorders associated with $\mathrm{CDH}$ are Fryns syndrome, Donnai-Barrow syndrome and others. Chromosomal abnormalities have been implicated in $\sim 15 \%$ of the cases. The most common chromosomal abnormalities are trisomy 18, isochromosome12p (Pallister-Killian syndrome), trisomy 13 , trisomy 21 , and 45,X. Chromosome structural abnormalities have also been described in association with CDH [Holder et al., 2007; Pober, 2008]. The deletions of 15q26.1 and 8p23.1 have been reported frequently in patients with $\mathrm{CDH}$.

\section{KARGER 125}

(c) 2015 S. Karger AG, Base

$1661-8769 / 15 / 0065-0248 \$ 39.50 / 0$

E-Mail karger@karger.com

www.karger.com/msy
Dr. Mitesh Shetty

Department of Medical Genetics, Manipal Hospital

98 HAL Airport Road

Bangalore 560017 (India)

E-Mail mitesh@manipalhospitals.com 
A del(15)(q26.1q26.2) (OMIM 142340, DIH1) has been reported in more than 2 dozen cases with the compelling evidence of the increased risk for abnormal diaphragm formation. Loss of this interval can result from one of several mechanisms such as de novo deletions, unbalanced translocations or formation of a ring chromosome 15. All patients had intellectual disability, growth retardation and/or additional birth defects such as craniofacial anomalies, cardiovascular malformations, hypoplastic genitalia or cryptorchidism, or an overlapping facial appearance with Fryns syndrome [Klaassens et al., 2007; Pober, 2008]. The COUP-TFII gene is located in chromosome $15 \mathrm{q} 26$ in a region recurrently deleted in individuals with CDH [Klaassens et al., 2005]. COUP-TFII, also known as NR2F2, is a transcription factor in the steroid/thyroid hormone receptor superfamily. It is expressed in the embryonic pleuroperitoneal folds in the early stage of development and in the diaphragm in the late days of gestation [Dingemann et al., 2012].

A $\operatorname{del}(8)(\mathrm{p} 23.1)$ (OMIM 222400, DIH2) is another $\mathrm{CDH}$ 'hot spot' revealed by cytogenetic and molecular cytogenetic studies [Shimokawa et al., 2005]. This region contains the candidate gene GATA4, known to be important for heart, lung and diaphragm development [Pober, 2008]. GATA4 is located in chromosome 8p23.1, a region recurrently deleted in individuals with $\mathrm{CDH}$. GATA4 is important for lung and diaphragm development in humans. GATA4 encodes a transcription factor that interacts with FOG2 during the morphogenesis of the heart [Holder et al., 2007].

There are a number of evidences that show there are certain genes and pathways which play a role in the development of $\mathrm{CDH}$. The retinoid acid signaling pathway and genes such as COUP-TFII, FOG2, GATA4, WTI, and SLIT3 are thought to be involved in the development of $\mathrm{CDH}$. Preliminary evidence came from a small study in which the levels of plasma retinol and retinol-binding protein in the cord blood of infants with $\mathrm{CDH}$ was found to be $50 \%$ lower than those in age-matched controls [Holder et al., 2007]. Vitamin A (retinol) and its derivatives such as retinoid are essential for the embryonic development of the diaphragm. COUP-TFII expression is upregulated by retinoid acid. Diaphragmatic hernia 1(DIH1) has been mapped to chromosome 15q26.1 (COUP-TFII), Diaphragmatic hernia 2(DIH2) to chromosome 8p23.1 (GATA4) and Diaphragmatic hernia 3 (DIH3) to chromosome 8q23 (ZFPM2). Submicroscopic deletions of $15 \mathrm{q} 26.1$ and $8 \mathrm{p} 23.1$ have been reported in several cases of $\mathrm{CDH}$. We therefore studied a total of 17 cases with $\mathrm{CDH}$ in pre- and postnatal samples to comple-
Table 1. Type of samples

\begin{tabular}{lll}
\hline & Samples $(\mathrm{n}=17)$ & Abnormal $(\mathrm{n}=1)$ \\
\hline Amniotic fluid & 5 & 1 \\
Cord blood & 6 & 0 \\
Chorionic villi & 1 & 0 \\
Peripheral blood & 5 & 0 \\
\hline
\end{tabular}

ment evidence and extend existing knowledge of the COUP-II and GATA4 genes with respect to previous research.

\section{Materials and Methods}

\section{Sample Details}

We studied a total of 17 samples with $\mathrm{CDH}$ (12 prenatal and 5 postnatal samples; tables 1-3). Peripheral blood was used for analysis in postnatal samples. Chorionic villi, amniotic fluid and cord blood were used in prenatal samples. Fetuses and children with $\mathrm{CDH}$ were included in the study. Fetuses with normal ultrasound were excluded from the study. Fetuses and children with common autosomal trisomy were also excluded.

\section{Karyotyping}

All pre- and postnatal samples were cultured and harvested. The chromosome slides were prepared and banded using standard protocols [Hungerford, 1965; Seabright, 1971; Priest and Rao, 1997]. Twenty well-spread and well-banded metaphases were captured using Olympus BX51 (Japan), analyzed and karyotyped using Applied Spectral Imaging BandView ver. 5.0 software, Israel. The chromosome abnormalities were identified and designated as per ISCN (2013) nomenclature.

\section{Fluorescence in situ Hybridization}

FISH analysis was used to precisely define the $15 \mathrm{q} 26.1$ and 8p23.1 deletion break points. Cytocell UK designed the custommade probe localized to $15 \mathrm{q} 26.1$ for the NR2F2 gene with BAC clones RP11-327J17, CTD-2027G2 and RP11-143C19. The SNRPN gene was used as a control. The BAC clone localized to 8 p23.1 was selected from the human DNA library in the UCSC genome browser and provided by BACPAC Resources (http:// bacpac.chori.org/home.htm). The BAC clone RP11-235I5 (GATA4) 180-200 kb was used. 8q11.1 was used as a control. DNA was isolated from cultured BACs, amplified and then labeled with digoxigenin 11-dUTP by nick translation according to standard protocols. FISH probes were hybridized onto the slides and detected using anti-DIG antibody tagged with rhodamine [Sambrook and Russell, 2001]. The probe and prepared slides were denatured, hybridized, washed, and counter stained. Slides were observed under an Olympus BX60, a fluorescence microscope using multi-bandpass filter [Pinkel et al., 1988; Ried et al., 1992]. Analysis of the slide was done using the Applied Spectral Imaging ver. 5.0. A minimum of 10-15 metaphases were analyzed, and a minimum of 3 metaphase pictures were captured. 
Table 2. Prenatal sample details

\begin{tabular}{|c|c|c|c|c|c|c|c|c|}
\hline $\begin{array}{l}\text { Sample } \\
\text { no. }\end{array}$ & \multicolumn{2}{|l|}{ Age } & Sex & $\begin{array}{l}\text { Consan- } \\
\text { guinity }\end{array}$ & Indications & Karyotype & FISH $15 q$ & FISH $8 \mathrm{p}$ \\
\hline $\mathrm{CDH} 1$ & 28 & 20 & M & no & $\mathrm{CDH}$ & normal & normal & normal \\
\hline $\mathrm{CDH} 2$ & 28 & 18 & M & no & CDH, IUGR & $\begin{array}{l}\operatorname{mos} 46, \operatorname{idic}(15)[12] \\
/ 46, \mathrm{r}(15)[6] / 46[2]\end{array}$ & abnormal & - \\
\hline CDH5 & 22 & 23 & $\mathrm{~F}$ & yes & $\mathrm{CDH}, \mathrm{DWM}$ & normal & normal & normal \\
\hline $\mathrm{CDH} 6$ & 24 & 22 & $\mathrm{~F}$ & no & $\mathrm{CDH}$, right-sided heterotaxy & normal & normal & normal \\
\hline $\mathrm{CDH7}$ & 26 & 22 & $\mathrm{M}$ & no & $\mathrm{CDH}$ & normal & normal & normal \\
\hline $\mathrm{CDH} 8$ & 22 & 24 & $\mathrm{M}$ & yes & $\begin{array}{l}\mathrm{CDH}, \mathrm{AVSD}, \mathrm{DWM}, \\
\text { ambiguous genitalia, } \\
\text { micrognathia, CTEV }\end{array}$ & normal & normal & normal \\
\hline $\mathrm{CDH} 12$ & 23 & 14 & $\mathrm{M}$ & no & $\mathrm{CDH}$ & normal & normal & normal \\
\hline
\end{tabular}

AVSD = Atrioventricular septal defect; CTEV = congenital talipes equinovarus; DWM = Dandy-Walker malformation; IUGR = intrauterine growth retardation.

Table 3. Postnatal samples with normal karyotypes and normal FISH results

\begin{tabular}{|c|c|c|c|c|}
\hline \multirow{2}{*}{$\begin{array}{l}\text { Sample } \\
\text { No. }\end{array}$} & \multicolumn{2}{|l|}{ Age } & \multirow[t]{2}{*}{ Sex } & \multirow[t]{2}{*}{ Indications } \\
\hline & patient & mother & & \\
\hline $\mathrm{CDH} 13$ & 1 day & 29 years & M & $\mathrm{CDH}$ \\
\hline CDH14 & 2 years, 1 month & 28 years & $\mathrm{F}$ & $\mathrm{CDH}$ \\
\hline $\mathrm{CDH} 15$ & 1 day & 26 years & $\mathrm{F}$ & $\mathrm{CDH}$ \\
\hline CDH16 & 20 months & 35 years & $\mathrm{M}$ & $\begin{array}{l}\mathrm{CDH}, \mathrm{ASD}, \\
\text { developmental } \\
\text { delay }\end{array}$ \\
\hline $\mathrm{CDH} 17$ & 2 years, 1 month & 26 years & M & $\mathrm{CDH}$ \\
\hline
\end{tabular}

ASD = Atrial septal defect. No consanguinity existent.

\section{Results}

One of the prenatal samples showed a mosaic pattern, dicentric chromosome 15 in 12 metaphases, ring chromosome 15 in 6 metaphases, and normal chromosomes in 2 metaphases analyzed (fig. 1). FISH study for 15q26.1 also showed a mosaic pattern, deletion in $80 \%$ and normal chromosomes in $20 \%$ of the metaphases (fig. 2). The rest of the samples did not show the deletion. A deletion 15 q26.1 was seen in one (8.33\%) of the prenatal samples and overall 1/17 (5.88\%). No deletion was seen for $8 \mathrm{p} 23.1$ (fig. 3) in all 17 samples analyzed. In this study, $70 \%$ of the samples were prenatal and the remaining 30\% were postnatal. In the prenatal cases, cord blood samples formed the majority with $50 \%$, followed by $42 \%$ of amniotic fluid and $8 \%$ of chorionic villi samples. Isolated $\mathrm{CDH}$ was seen in 10/17 (59\%) patients, while 7/17 (41\%) had additional malformations. Of these patients, a heart defect was seen in 4/7(57\%). All CDH were observed to be left-sided hernias. Consanguinity was seen in $\sim 17.65 \%$ of $\mathrm{CDH}$ patients. None of the mothers with advanced maternal age had a baby with $\mathrm{CDH}$. In fact, the majority (94\%) of mothers were in the age group of 21-30 years.

In the 15q26.1 deleted case, amniocentesis was done at 18 weeks of gestation for $\mathrm{CDH}$, intrauterine growth restriction and triple test positive for Patau syndrome. The mother was primigravida in a nonconsanguineous marriage. The karyotype of the parents was normal. In her next pregnancy, nuchal translucency, anomaly and growth scan were normal, and no invasive procedure was performed. She delivered a normal healthy baby girl. All prenatal cases were terminated and all postnatal cases were operated and were doing fine. To the best of our 


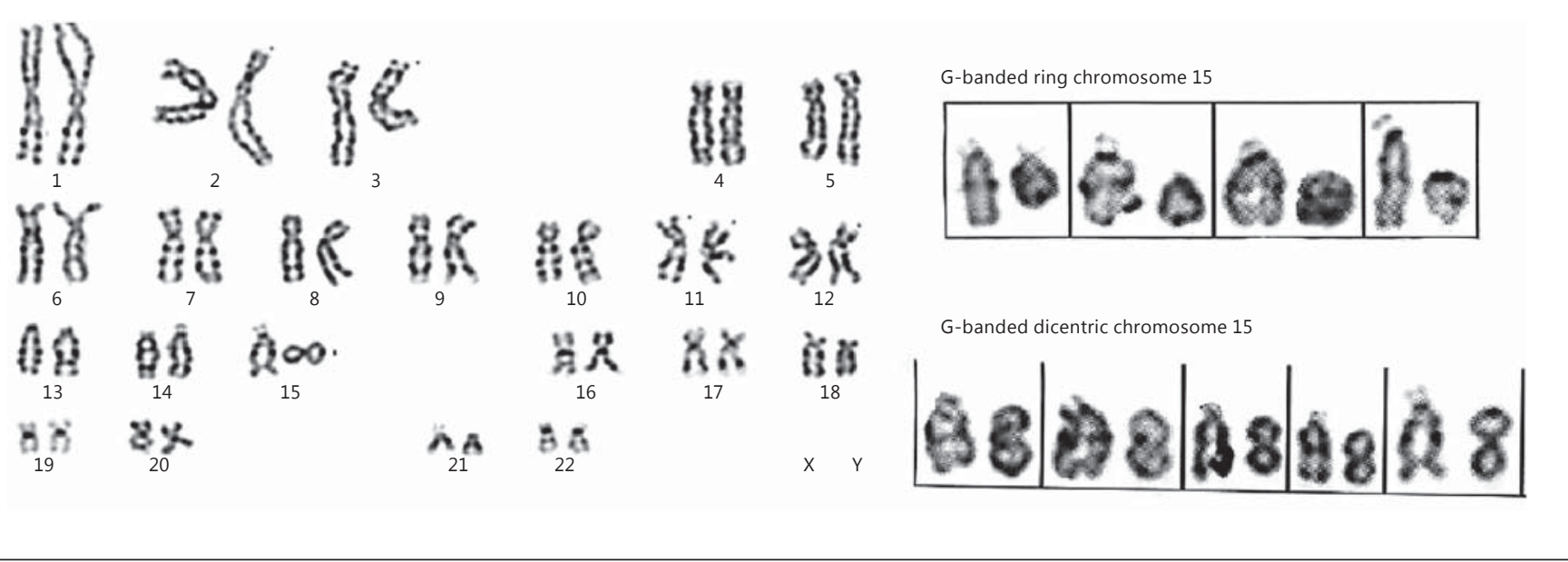

Fig. 1. a Karyotype showing the dicentic chromosome 15. b Comparison of chromosome 15 showing ring and dicentric chromosomes.
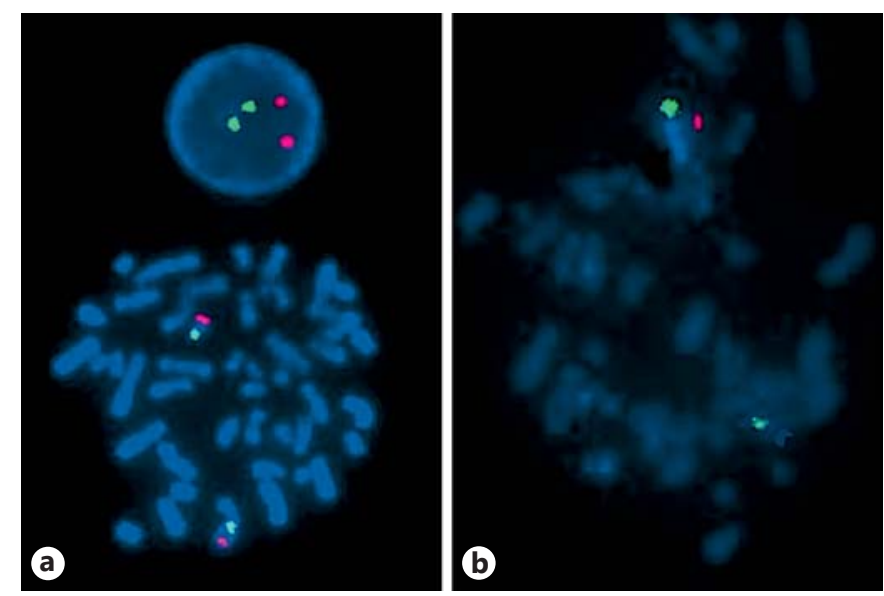

Fig. 2. FISH study showing a mosaic pattern of deletion $15 q 26.1$. a Normal signal. b Deletion 15q26.1 (Spectrum Orange: RP11327J17, CTD-2027G2 and RP11-143C19, COUP-II; Spectrum Green: $15 \mathrm{q} 11$, SNRPN control).

knowledge, this is the first prenatal or postnatal submicroscopic deletion study for $\mathrm{CDH}$ from India and the first case of a prenatally diagnosed deletion 15q26.1 from India.

\section{Discussion}

In this study, we analyzed 17 patients with $\mathrm{CDH}$ and identified one case with a 15q26.1 deletion. Klaassens et al. [2005] studied 200 patients with $\mathrm{CDH}$ and identified

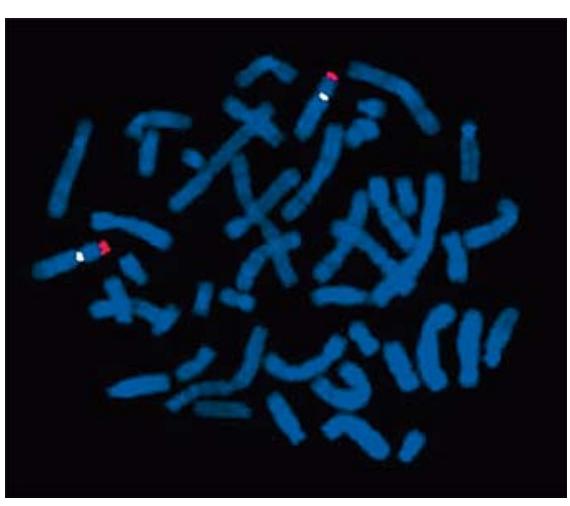

Fig. 3. FISH study showing a normal signal pattern for 8 p23.1 (Spectrum Orange RP11-235I5, GATA4 and Spectrum Green for 8q11.1, control).

3 patients with a $15 \mathrm{q}$ deletion. They defined $\sim 5 \mathrm{Mb}$ at chromosome 15q26.1q26.2, a minimally deleted region for CDH by use of FISH and array CGH data. One of their patients had a ring chromosome 15 . CDH has not yet been described as a main feature in ring chromosome 15 syndrome. The key features of ring chromosome 15 include growth retardation, microcephaly, variable mental retardation, and delayed bone age [Butler et al., 1988]. In the ring chromosome 15 in this present study, the fetus had $\mathrm{CDH}$ and intrauterine growth retardation. Britto et al. [2014] and Hatem et al. [2007] each reported 
a case of prenatal diagnosis of $\mathrm{CDH}$ and intrauterine growth retardation in a fetus with ring chromosome 15 similar to our study. Klaassens et al. [2007] reported 2 patients with a deletion of 15q26 and the phenotype consists of intrauterine growth retardation, left-sided $\mathrm{CDH}$, cardiac anomalies, and characteristic facial features, similar to those seen in Fryns syndrome. They proposed that when this combination of birth defects is identified, either pre- or postnatally, further investigations to confirm or exclude a deletion of $15 \mathrm{q} 26$ are indicated. Slavotinek et al. [2005] identified submicroscopic chromosome deletions in 3 probands by array CGH who had previously been diagnosed with Fryns syndrome and had normal karyotypes. Two female infants were found to have microdeletions involving $15 \mathrm{q} 26.2$, and one male infant had a deletion in band 8p23.1. Several recent reports describe nonisolated $\mathrm{CDH}$ cases with apparently normal karyotypes but abnormalities were detected by array CGH. Array CGH should be considered in prenatally diagnosed cases of CDH [Holder et al., 2007]. Brady et al. [2013] studied copy number variations using micro array in 75 fetuses with $\mathrm{CDH}$ and found haploinsufficiency of NR2F2.

Wat et al. [2009] described a monozygotic twin with interstitial deletion of 8 p23.1 by array CGH in the amniotic fluid. One twin had $\mathrm{CDH}$ and a heart defect, while the other twin only had a heart defect. They suggested that haploinsufficiency of other genes, in addition to GATA4, may play a role in severe heart defects and CDH associated with 8p23.1 deletions. Deletions involving 8 p23.1 have been described in 9 patients with $\mathrm{CDH}$ [Pober, 2008]. In our study, we did not detect an 8p23.1 deletion, although we had 4 patients with $\mathrm{CDH}$ and heart defects. Yu et al. [2014] used whole exome sequencing in 2 families with $\mathrm{CDH}$ and congenital heart disease and identified mutations in GATA6. The use of new technologies will enhance our understanding of the heterogeneous molecular etiology of $\mathrm{CDH}$ [Longoni et al., 2014].

In their prospective study, Harrison et al. [1994] observed 58\% mortality among CDH diagnosed before 24 weeks' gestation despite optimal postnatal care. Prenatally detected cases had a reduced survival to surgery rate compared to postnatally detected rates [Bhat et al., 2008]. Colvin et al. [2005] reported that prenatal diagnosis itself was an important predictor of mortality rates for liveborn infants. Nearly half of the prenatally diagnosed fetuses underwent elective termination of pregnancy. This large number of fetal terminations confounds the accurate assessment of the true outcomes of this condition. In our study, all prenatally diagnosed cases had also opted for termination of pregnancy. It is worthwhile to search for a 15q26.1 deletion in fetuses with $\mathrm{CDH}$ as this has a high mortality rate. This will enable appropriate parental counseling and, hence, decision making [Schlembach et al., 2001; Hengstschläger et al., 2004; Klaassens et al., 2007; Pober, 2008].

The challenge in the present study was to detect samples that met our criteria. In the antenatal period, it was difficult to recognize samples after ruling out common autosomal trisomy. As CDH was detected before birth, all patients opted for termination of pregnancy. Thus, acquiring postnatal samples was also difficult. The description of multiple genetic syndromes associated with $\mathrm{CDH}$ highlights the importance of a careful evaluation of patients with $\mathrm{CDH}$ [Holder et al., 2007; Pober, 2008]. Such an evaluation may have an influence on the couple's decision, including the possibility of terminating pregnancy. Understanding the genetic factors associated with $\mathrm{CDH}$ may make it possible to devise preventive strategies or to improve therapeutic interventions [Pober, 2008]. Every child with $\mathrm{CDH}$ and additional malformations or whenever a $\mathrm{CDH}$ is detected by prenatal ultrasound should be karyotyped and examined to exclude a 15q26.1 deletion. In case of a normal karyotype and no deletion of $15 \mathrm{q} 26.1, \mathrm{CDH}$ can be corrected by percutaneous fetoscopic endoluminal tracheal occultion prenatally, or delivery should be planned at a tertiary care center where $\mathrm{CDH}$ can be managed postnatally.

\section{Acknowledgment}

We would like to thank Cytocell Ltd., UK, for assistance with the FISH probe for 15q26.1.

\section{Statement of Ethics}

The study was approved by the Institutional Ethics Committee. Informed consent was obtained from each family.

\section{Disclosure Statement}

The authors have no conflicts of interest to declare. 


\section{References}

Bhat YR, Kumar V, Rao A: Congenital diaphragmatic hernia in a developing country. Singapore Med J 49:715-718 (2008).

Brady PD, DeKoninck P, Fryns JP, Devriendt K, Deprest JA, Vermeesch JR: Identification of dosage-sensitive genes in fetuses referred with severe isolated congenital diaphragmatic hernia. Prenat Diagn 33:1283-1292(2013).

-Britto IS, Regina Silva Herbest S, Tedesco GD, Drummond CL, Bussamra LC, et al: Prenatal diagnosis of a fetus with ring chromosomal 15 by two- and three-dimensional ultrasonography. Case Rep Obstet Gynecol 2014:495702 (2014).

Butler MG, Fogo AB, Fuchs DA, Collins FS, Dev VG, Phillips JA 3rd: Two patients with ring chromosome 15 syndrome. Am J Med Genet 29:149-154(1988).

Colvin J, Bower C, Dickinson JE, Sokol J: Outcomes of congenital diaphragmatic hernia: a population-based study in Western Australia. Pediatrics 116:e356-363 (2005).

Dingemann J, Doi T, Ruttenstock EM, Gosemann $\mathrm{JH}$, Puri P: COUP-TFII gene expression is upregulated in embryonic pleuroperitoneal folds in the nitrofen-induced congenital diaphragmatic hernia rat model. Eur J Pediatr Surg 22:21-25 (2012).

-Harrison MR, Adzick NS, Estes JM, Howell LJ: A prospective study of the outcome for fetuses with diaphragmatic hernia. JAMA 271:382384 (1994).

-Hatem E, Meriam BR, Walid D, Adenen M, Moez G, Ali S: Molecular characterization of a ring chromosome 15 in a fetus with intra uterine growth retardation and diaphragmatic hernia. Prenat Diagn 27:471-474 (2007).

Hengstschläger M, Mittermayer C, Repa C, Drahonsky R, Deutinger J, Bernaschek G: Association of deletions of the chromosomal region 15q24-ter and diaphragmatic hernia: a new case and discussion of the literature. Fetal Diagn Ther 19:510-512 (2004).
Holder AM, Klaassens M, Tibboel D, de Klein A, Lee B, Scott DA: Genetic factors in congenital diaphragmatic hernia. Am J Hum Genet 80: 825-845 (2007).

Hungerford DA: Leukocytes cultured from small inocula of whole blood and the preparation of metaphase chromosomes by treatment with hypotonic KCl. Stain Technol 40:333-338 (1965).

ISCN (2013): An International System for $\mathrm{Hu}$ man Cytogenetic Nomenclature, Shaffer LG, McGowan-Jordan J, Schmid M (eds) (Karger, Basel 2013).

Klaassens M, Dooren M, Eussen HJ, Douben H, den Dekker AT, et al: Congenital diaphragmatic hernia and chromosome 15q26: determination of a candidate region by use of fluorescent in situ hybridization and array-based comparative genomic hybridization. Am J Hum Genet 76:877-882 (2005).

Klaassens M, Galjaard RJ, Scott DA, Brüggenwirth HT, van Opstal D, et al: Prenatal detection and outcome of congenital diaphragmatic hernia $(\mathrm{CDH})$ associated with deletion of chromosome 15q26: two patients and review of the literature. Am J Med Genet A 143A:2204-2212 (2007).

Longoni M, High FA, Russell MK, Kashani A, Tracy AA, et al: Molecular pathogenesis of congenital diaphragmatic hernia revealed by exome sequencing, developmental data, and bioinformatics. Proc Natl Acad Sci USA 111: 12450-12455 (2014).

Pinkel D, Landegent J, Collins C, Fuscoe J, Segraves $\mathrm{R}$, et al: Fluorescence in situ hybridization with human chromosome-specific libraries: detection of trisomy 21 and translocations of chromosome 4. Proc Natl Acad Sci USA 85:9138-9142 (1988).
Pober BR: Genetic aspects of human congenital diaphragmatic hernia. Clin Genet 74:1-15 (2008).

Priest JH, Rao KW: Prenatal chromosome diagnosis, in Barch MJ, Knutsen T, Spurbeckeds JL (eds): The AGT Cytogenetics Laboratory Manual, ed 3, pp 199-258 (Lippincott-Raven Publisher, Philadelphia 1987).

Ried T, Baldini AR, Ward DC: Simultaneous visualization of seven different DNA probes by in situ hybridization using combinatorial fluorescence and digital imaging microscopy. Proc Natl Acad Sci USA 89:1388-1392 (1992).

Sambrook J, Russell DW: Working with bacterial artificial chromosomes; in Molecular Cloning: A Laboratory Manual, ed 3, pp 4.48-4.57 (CSHL Press, New York 2001).

Schlembach D, Zenker M, Trautmann U, Ulmer R, Beinder E: Deletion 15q24-26 in prenatally detected diaphragmatic hernia: increasing evidence of a candidate region for diaphragmatic development. Prenat Diagn 21:289292(2001).

Seabright M: A rapid banding technique for human chromosomes. Lancet 2:971-972 (1971).

- Shimokawa O, Miyake N, Yoshimura T, Sosonkina N, Harada N, et al: Molecular characterization of $\operatorname{del}(8)(\mathrm{p} 23.1 \mathrm{p} 23.1)$ in a case of congenital diaphragmatic hernia. Am J Med Genet A 136:49-51 (2005).

Slavotinek A, Lee SS, Davis R, Shrit A, Leppig KA, et al: Fryns syndrome phenotype caused by chromosome microdeletions at $15 \mathrm{q} 26.2$ and 8p23.1. J Med Genet 42:730-736 (2005).

Wat MJ, Shchelochkov OA, Holder AM, Breman AM, Dagli A, et al: Chromosome 8p23.1 deletions as a cause of complex congenital heart defects and diaphragmatic hernia. Am J Med Genet A 149A:1661-1677 (2009).

$\checkmark$ Yu L, Bennett JT, Wynn J, Carvill GL, Cheung $\mathrm{YH}$, et al: Whole exome sequencing identifies de novo mutations in GATA6 associated with congenital diaphragmatic hernia. J Med Genet 51:197-202 (2014). 